\title{
Anemia and perioperative blood transfusion in patients with colorectal cancer
}

\section{Luis Felipe Cuéllar-Guzmán ${ }^{1 *}$ and Crisenry Brito-Baños ${ }^{2}$}

${ }^{1}$ Head of the Department of Anesthesiology and Associate Professor of the High Specialty in Oncologic Anesthesiology Course; ${ }^{2}$ Resident of the High Specialty in Oncologic Anesthesiology Course. Instituto Nacional de Cancerología, Ciudad de México, Mexico

\section{Abstract}

Colorectal cancer is among the most prevalent worldwide. In Mexico, it represents one of the most common causes of death. A high percentage of oncologic patients will suffer anemia during the disease, thus, perioperative blood transfusion (PBT) is a common practice. A known effect of PBT is its negative immunomodulation. Both, anemia and PBT have been associated with recurrence and mortality in oncologic patients, with the colorectal cancer group been the most affected. Thanks to surgical development and minimally invasive techniques, the volume of blood losses has been reduced. Also, current restrictive transfusion strategies have allowed a decrease in intraoperative use of red blood concentrates during the last decades. The decision to transfuse most not be based in hemoglobin. Currently there is no one single criteria that can be used as a sole indication to transfuse.

Key words: Colorectal neoplasm. Blood transfusion. Anemia. Recurrence. Mortality.

\section{Correspondence:}

*L.F. Cuéllar-Guzmán

E-mail: Icuellar@incan.edu.mx
Date of reception: 08-08-2017

Date of acceptance: 10-10-2017

DOI: 10.24875/j.gamo.M18000148
Available online: 24-02-2018 Gac Mex Oncol. 2017;16(6):335-339 CC BY-NC-ND license (http://creativecommons.org/licenses/by-nc-nd/4.0/) 


\section{Introduction}

Colorectal cancer is one of the most prevalent malignancies world-wide ${ }^{1}$. It is the third most commonly diagnosed cancer and the second one in women, with 1.4 million cases and 693,000 deaths being estimated in $2012^{2}$. In our country, it is at third place in frequency for both genders, with an estimated mortality of $6 \%{ }^{3}$.

Anemia occurs in up to $50 \%$ of cancer patients sometime during the course of their disease ${ }^{4}$. Up to $40 \%$ of oncologic patients experience cancer-associated anemia that requires preoperative blood transfusion ${ }^{5}$.

In the USA, $19.8 \%$ of transfused blood products in 2011 are estimated to have been used in patients undergoing surgical procedures ${ }^{6}$. Approximately $15.1 \%$ of resources in blood products are assigned to patients with hematologic/oncologic pathologies?.

Red blood cell concentrates perioperative transfusion has been reported in up to $85 \%$ of patients with colorectal cancer ${ }^{8}$.

Clinical evidence on blood transfusion-associated immunomodulation has been available since 1973, in the study conducted by Opelz et al., where they confirmed that receptor patients who were transfused with allogeneic blood had renal graft better functioning ${ }^{9}$. Gantt suggested the possibility of transfusion-associated immunomodulation affecting cancer patients' prognosis ${ }^{10}$. In 1982, Burrows and Tartter were the first ones to propose a relationship between allogeneic transfusion and prognosis in patients with colon cancer ${ }^{11}$.

\section{Anemia in the oncologic patient}

Anemia, both at initiation and in the course of disease, is of multifactorial origin. It can be due to a combination of factors such as iron deficiency, occult gastrointestinal bleeding, systemic inflammation with high levels of hepcidin, or secondary to chemotherapy ${ }^{12}$.

Wu et al. observed an association between preoperative anemia and worse outcomes after non-cardiac major surgery ${ }^{5}$.

Leichtle et al. studied the role of preoperative anemia in patients undergoing colorectal surgery. They included 23,348 patients of the National Surgical Quality Improvement Program ${ }^{\circledR}$ (NSQIP) database undergoing colectomy, and found that anemia is an independent risk factor for the presence of complications (severe: $R R=1.83$, moderate: $R R=2.19$, mild: $R R=1.49)^{13}$.

The hemoglobin concentration that is associated with higher morbidity and mortality in the surgical oncologic population appears to be $8 \mathrm{~g} / \mathrm{dL}$. The probability of death in the perioperative period increases 2.5 -fold with each gram of hemoglobin under $8 \mathrm{~g} / \mathrm{dL}^{14}$.

\section{Transfussion and immunity}

It is an acknowledged phenomenon that blood products administration has deep negative effects on the immune system, a condition that is known as transfusion-related immunomodulation (TRIM). The TRIM mechanisms include cytotoxic cells and monocyte activity suppression, immunosuppressant prostaglandins release, inhibition of interleukin 2 (IL-2) production and increase in T cells suppressing activity ${ }^{15,16}$ (Table 1 ).

\section{Transfusion in the course of disease}

Vamvakas et al. studied transfusion in patients undergoing elective colorectal resection, and found that the risk of postoperative infection increases by $14 \%$ per transfused packed red blood cell unit ${ }^{17}$.

In a NSQIP review that included 38,926 patients undergoing oncologic surgery, intraoperative transfusion was found to be associated with higher 30-day mortality, increased complications and prolonged hospital stay $^{18}$.

Acheson et al., in a systematic review that included 20,795 patients with colorectal cancer undergoing surgery, found that allogeneic transfusion of packed red blood cells was associated with higher mortality, higher disease recurrence and prolonged hospital stay ${ }^{19}$.

In a study that included 597 patients undergoing surgery for rectal cancer, Jagoditsch et al. found higher 60-day mortality in patients who were transfused with more than 3 packed red blood cell units during the perioperative period. The number of units or the type of transfusion (autologous or allogeneic) did not influence on local recurrence, distant metastasis or recurrence-free period ${ }^{20}$.

Gunka et al. found that patients receiving 3 or more units of packed red blood cells had significantly lower 5-year survival, shorter disease-free period and higher incidence of distant recurrence ${ }^{21}$.

Kneuertz et al., in their retrospective study of 220 patients undergoing pancreaticoduodenectomy, found that $67 \%$ were transfused in the perioperative period, with this group being the one that had shorter recurrence-free time and lower survival. According to timing, patients who were postoperatively transfused were associated with the worst outcomes ${ }^{22}$.

Warschkow et al., in a study that included 401 patients with stage I to III rectal cancer undergoing 
Table 1. Biological mediators related to post-transfusion immunomodulation and tumor growth

\begin{tabular}{|l|l|}
\hline Biological mediator & Tumor activity \\
\hline $\begin{array}{l}\text { Cytokines } \\
\text { TH1 (IL-2, IFN- } \gamma \text { ) } \\
\text { TH2 (IL-4, IL-5, IL-10) }\end{array}$ & $\begin{array}{l}\text { Anti-tumor } \\
\text { Pro-tumor }\end{array}$ \\
\hline $\begin{array}{l}\text { Eicosanoids } \\
\text { Thromboxane A3 }\end{array}$ \\
PGE2, PG12 & Pro-tumor \\
\hline $\begin{array}{l}\text { Growth factors } \\
\text { TGF- } \beta\end{array}$ & Pro-tumor \\
VEGF & \\
PGDF-D & Pro-tumor \\
IGF & Pro-tumor \\
\hline
\end{tabular}

IFN: interferon; IGF: insulin-like growth factor; IL: interleukin; PG: prostaglandin; PGDF: platelet-derived growth factor; TH: T helper lymphocyte; TGF: transforming growth factor; VEGF: vascular endothelial growth factor. Adapted from Cata JP et al. 15 .

curative resection with a mean follow-up of 34.2 months, found that blood transfusion was associated with a $119 \%$ higher mortality risk (HR $=2.19)$; however, in their propensity analysis, blood transfusion did not increase the mortality risk $(\mathrm{HR}=1.02)$, thus concluding that oncologic negative results in patients who received blood transfusion were the consequence of the circumstances that drove to the need of transfusion ${ }^{23}$.

In a cohort study carried out in Sweden that included patients with stage I-III colorectal cancer undergoing curative surgery, preoperative anemia was found to increase the mortality risk $(H R=2.1)$, without being associated with the risk for recurrence ${ }^{24}$. In the case of blood transfusion, no association was found with mortality or recurrence risk ${ }^{24}$.

\section{Transfusion tendency over time}

Thanks to the advances in surgical techniques, currently minimally invasive, a decrease in intraoperative blood loss has been achieved. This, together with a tendency towards more restrictive transfusion strategies, has reflected in less perioperative transfusions in cancer patients. In the study by Acheson et al., a change in transoperative transfusion tendency was observed, which was at $68.6 \%$ in $1980-1989,59.9 \%$ in $1990-1999$ and $45.6 \%$ in $2000-2009^{19}$. Jagoditsch et al. report a decrease in perioperative transfusion, which went from $84 \%$ in $1984-1990$ to $58 \%$ in $1997-2003^{20}$.

\section{Anemia, transfusion and recurrence}

The combination of perioperative moderate-to-severe anemia and blood transfusion induces changes in several physiological processes' homeostasis, including endothelial function, complement activation, inflammatory response and immune function. All this has been associated with cancer recurrence ${ }^{14}$.

Recurrence depends on preoperative nutritional status, performance status, presence of anemia, type and stage of the tumor, resectability degree, duration and type of anesthesia, blood loss, perioperative response to surgical stress and on the presence of postoperative complications.

Recent interest on perioperative anesthetic management in the oncologic patient has focused on strategies and protocols that include regional anesthesia, decreased use of inhaled anesthetics and opioids and blood transfusion goals, which can influence on tumor spread $^{15}$.

Approximately $90 \%$ of cancer deaths are secondary to primary tumor dissemination and metastasis ${ }^{16}$.

In a meta-analysis that evaluated the role of perioperative blood transfusion in colorectal cancer recurrence, Amato and Pescatori found an odds ratio (OR) of 1.42 for recurrence in transfused patients. The risk was higher according to the number of transfused units: with 1-2 units, OR was 1.4; with 3-4 units, OR was 1.69 and with more than 5 units, OR was 2.02. Transfusion timing (preoperative, intraoperative or postoperative) showed no difference in the risk of recurrence $(30 \%$, $32 \%$ and $30 \%$, respectively 25 .

Current evidence indicates that perioperative blood transfusion is associated with recurrence in patients with colorectal, lung and hepatobilliary cancer. In the setting of prostate cancer, the association is weak or inexistent. In other types of cancer, evidence is still inconclusive $^{26}$ (Fig. 1).

\section{Transfusion strategies}

The decision to transfuse should not be based on hemoglobin concentration. Currently there is not a sole criterion that can be used as an indication to transfuse. In general terms, the indications for packed red blood cells transfusion include the treatment of tissue hypoxia secondary to low hemoglobin levels, acute anemia owing to trauma or surgical bleeding, anemia in patients receiving chemotherapy and chronic anemia-associated cardiovascular decompensation ${ }^{27}$. 


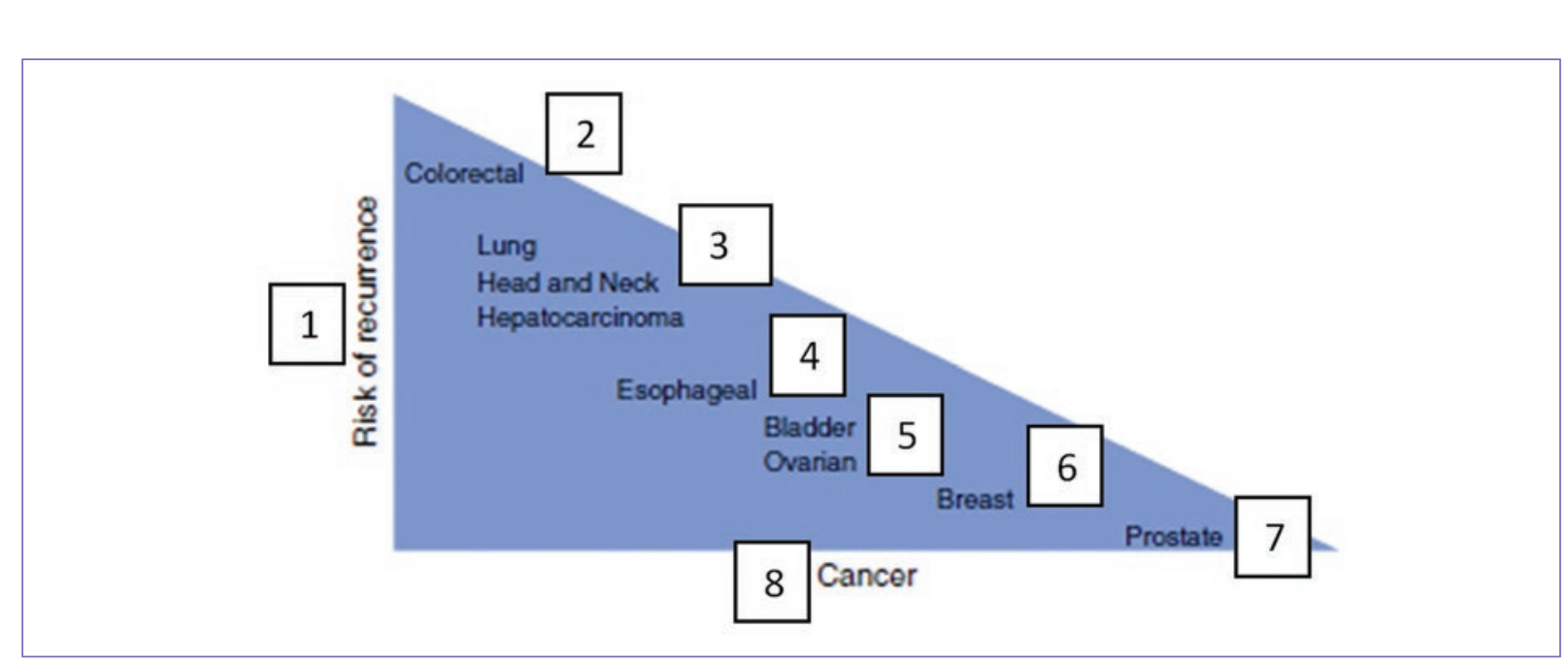

Figure 1. Risk of recurrence in case of transfusion according to current evidence (adapted from Velázquez JF et al. ${ }^{26}$ ).

Prescott et al. studied the safety and efficacy of transfusion restrictive strategies in a meta-analysis that included surgical and non-surgical oncologic patients, and found that $36 \%$ less perioperative transfusion was achieved with such a strategy, with no statistically significant difference in 30-day mortality in comparison with a liberal strategy 28 .

In a double-blind, randomized, controlled study that included patients admitted to an intensive care unit after having undergone abdominal oncologic surgery, Almeida et al. found a lower incidence of complications at 30 days in the liberal transfusion group $(\mathrm{Hb}<9 \mathrm{~g} / \mathrm{dL})$ in comparison with the restrictive transfusion group $(\mathrm{Hb}$ $<7 \mathrm{~g} / \mathrm{dL}$ ) $(19.6 \%$ vs. $35.6 \%)$. Another important finding was that 60-day mortality was lower in the liberal transfusion group ${ }^{29}$.

In spite of the elevated prevalence of anemia and of the liberal use of transfusion in several oncologic studies, there is limited information justifying anemia correction by means of blood transfusion ${ }^{30}$.

\section{Conclusion}

Blood transfusion during the perioperative period remains a subject of debate because the best indicator to transfuse has not yet been established. In the case of the oncologic patient, evidence remains controversial, although, in colorectal cancer, most studies point at this being the most affected group by the practice of transfusion. Further studies are required, especially of the prospective nature, to enable having more consistent evidence on the deleterious effects of blood transfusion.

\section{Conflict of interests}

Both authors declare not having any conflicts of interests relevant to this manuscript.

\section{References}

1. Center MM, Jemal A, Ward E. International trends in colorectal cancer incidence rates. Cancer Epidemiol Biomarkers Prev. 2009;18:1688-94.

2. Lindsay A, Bray F, Siegel R, et al. Global cancer statistics, 2012. CA Cancer J Clin. 2015;65:87-108.

3. Ferlay J, Soerjomataram I, Ervik M, et al. GLOBOCAN 2012 v1.0, Cancer incidence and mortality worldwide: IARC CancerBase No. 11 [Internet]. Lyon, France: International Agency for Research on Cancer; 2013 [citado el 20/07/2017]. Disponible en: http://globocan.iarc.fr.

4. Uceda ME, Rodríguez JN, Sánchez JL, et al. Transfusion in palliative cancer patients: a review of the literature. J Palliat Med. 2014; 17:88-104.

5. Wu WC, Schifftner TL, Henderson WG, et al. Preoperative hematocrit levels and post-operative outcomes in older patients undergoing noncardiac surgery. JAMA. 2007;297:2481-8.

6. Whitaker B. Report of the US Department of Health and Human Services. The 2011 National Blood Collection and Utilization Survey Report. 2011. Rockville, MD: US Department of Health and Human Services; 2015.

7. Goubran HA, Elemary M, Radosevich M, et al. Impact of Transfusion on Cancer Growth and Outcome. Cancer Growth Metastasis. 2016:9:1-8.

8. Jakobsen Eb, Eickhoff $\mathrm{JH}$, Andersen J, et al. Perioperative blood transfusion and recurrence and death after resection of cancer of the colon and rectum. Scand J Gastroenterol. 1990;25:435-22.

9. Opelz G, Sengar DP, Mickey MR, et al. Effect of blood transfusions on subsequent kidney transplants. Transplant Proc. 1973;5(1):253-9.

10. Gantt CL. Red blood cells for cancer patients. Lancet. 1981;2(8242):363.

11. Burrows L, Tartter P. Effect of blood transfusión on colonic malignancy recurrent rate. Lancet. 1982;2:662.

12. Vignot S, Spano JP. Anemia and colorectal cancer. Bull Cancer. 2005;92:432-8.

13. Leichtle S, Mouawad N, Lampman R, et al. Does Preoperative Anemia Adversely Affect Colon and Rectal Surgery Outcomes? J Am Coll Surg. 2011;212:187-94.

14. Cata JP. Perioperative anemia and blood transfusions in patients with cancer: when the problem, the solution, and their combination are each associated with poor outcomes. Anesthesiology. 2015;122(1):3-4.

15. Cata JP, Wang H, Gottumukkala V, et al. Inflammatory response, immunosuppression, and cancer recurrence after perioperative blood transfusions. Br J Anaesth. 2013;110(5):690-701.

16. Dionigi G, Rovera F, Boni L, et al. The impact of perioperative blood transfusion on clinical outcomes in colorectal surgery. Surg Oncol. 2007;16(1):S177-82

17. Vamvakas E, Carven J, Hibberd P. Blood transfusión and infection after colorectal cancer surgery. Transfusion. 1996;36:1000-8. 
18. Al-Refaie $\mathrm{W}$, Parsons $\mathrm{H}$, Markin $\mathrm{J}$, et al. Blood transfusion and cancer surgery outcomes: A continued reason for concern. Surgery. 2012; 152:344-54

19. Acheson A, Brookes M, Spahn D. Effects of allogeneic red blood cell transfusions on clinical outcomes in patients undergoing colorectal cancer surgery. a systematic review and meta-analysis. Ann Surg. 2012;256:235-44.

20. Jagoditsch M, Pozgainer P, Klinger A, et al. Impact of blood transfusions on recurrence and survival after rectal cancer surgery. Dis Colon Rectum. 2006;49:1116-30.

21. Gunka I, Dostalik J, Martinek L, et al. Impact of blood transfusion on survival and recurrence in colorectal cancer surgery. Indian J Surg. 2013;75(2):94-101.

22. Kneuertz $\mathrm{P}$, Sameer $\mathrm{H}, \mathrm{Chu} \mathrm{C}$, et al. Effects of perioperative red blood cell transfusion on disease recurrence and survival after pancreaticoduodenectomy for ductal adenocarcinoma. Ann Surg Oncol. 2011; 18:1327-34.

23. Warschkow R, Güller U, Köberle D, et al. Perioperative blood transfusions do not impact overall and disease-free survival after curative rectal cancer resection: a propensity score analysis. Ann Surg. 2014;259(1):131-8.
24. Mörner M, Edgren G, Martling A, et al. Preoperative anaemia and perioperative red blood cell transfusion as prognostic factors for recurrence and mortality in colorectal cancer-a Swedish cohort study. Int J Colorectal Dis. 2017;32(2):223-32.

25. Amato A, Pescatori M. Perioperative blood transfusions for the recurrence of colorectal cancer. Cochrane Database Syst Rev. 2006; (1):CD005033

26. Velázquez JF, Cata JP. Transfusions of blood products and cancer outcomes. Rev Esp Anestesiol Reanim. 2015;62(8):461-7.

27. Watkins T, Surowiecka M, McCullough J. Transfusion indications for patients with cancer. Cancer Control. 2015;22(1):38-46.

28. Prescott L, Taylor J, Lopez-Olivo M, et al. How low should we go: A systematic review and meta-analysis of the impact of restrictive red blood cell transfusion strategies in oncology. Cancer Treatment Reviews. 2016;46:1-8.

29. de Almeida JP, Vincent JL, Galas FR, et al. Transfusion requirements in surgical oncology patients: a prospective, randomized controlled trial. Anesthesiology. 2015;122(1):29-38.

30. Salpeter SR, Buckley JS, Chattarjee S. Impact of more restrictive blood transfusion strategies on clinical outcomes: a meta-analysis and systematic review. Am J Med. 2014;124-31. 